(a) $\mathrm{j}=-287,16^{\circ}$ oder (a) $\mathrm{r}=-220,16^{\circ}$. Versuch 6 und 7 verglichen mit 3 und 4 und den bis jetzt bekannten Versuchen üher das Rotationsvermögen des Chinins zeigen, wie wichtig es ist, dieses Alkaloid auf die von de Vry und Alluard erwähnte Art zu reinigen, wenn es zu genaueren Rotationsversuchen benutzt werden soll. (Compt. rend. T.59. daraus im Journ. f. pract. Chemie).

$B$.

\title{
Bereitung von Chinoidinum depuratum.
}

Von J. E. de Vry.

In der Anleitung zur Bereitung und Prüfüng von Heilmitteln, welche nicht in der Niederländischen Pharmacopöe aufgenommen sind, wird vorgeschrieben, das Chinoidin aus dem Handel zu reinigen, indem man dasselbe in verdünnter Essigsäure auflöst und die filtrirte Auflösung mit Ammoniakflüssigkeit präcipitirt. Diese Vorschrift ist in der zweiten Ausgabe des Werkchens, welche im Jahre 1861 erschien, unverändert aufgenommen. In der dritten Ausgabe vom Jahre 1865 vermisse ich zu meinem Leidwesen den Artikel Chinoidinum depuratum und achte es daher für angemessen, eine Reinigungsmethode zu empfehlen, da der Apotheker nur das gereinig te gebrauchen kann.

Während ich mich aufs Neue damit beschäftigte, das Chinoidin zu untersuchen, erinnerte ich mich, dass Pasteur von dem damals beschriebenen Chinicin und Cinchonicin sagte, dass beide aus Auflösungen von Ammoniaksalzen bei gewöhnlicher Temperatur Ammoniak entwickeln. Die Ansicht, dass der amorphe Bestandttheil des Chinoidins vielleicht identisch mit dem Chinicin oder Cinchonicin von Pasteur sein könnte, gab mir Anleitung, die Wirkung der Auflösung eines Ammoniaksalzes auf Chinoidin bei gewöhnlicher Temperatur zu untersuchen, wobei ich fand, dass 9 Theile Chinoidin durch anhaltendes Reiben und Kneten in einem Mörser mit einer verdünaten Auflösung von zwei Theilen neutralem oxalsauren Ammoniak ganz aufgelöst wurden, wobei nur unbedeutende Unreinigkeiten zurückblieben. Die Menge dieser ungelöst bleibenden Stoffe ist sehr verschieden beim Chinoidin von verschiedenem Ursprung, woraus dann von selbst folgt, dass unreines Chinoidin nie in einer guten Apotheke dispensirt werden darf. So fand ich,z. B. bei Behandlung des Chinoidins aus der Chininfabrik des Dr. Z im mer in Frankfurt am Main 
nur $31 / 2$ Procent Unreinigkeiten, während diese bei Chinoidin aus einer andern Fabrik nicht weniger als 30 Procent betrugen. Während die Auflösung des Chinoidins in ëiner kalten Auflösung eines Ammoniaksalzes mir bei dem ersten Versuche glückte, musste ich dagegen bei einem folgenden Versuche mit demselben Chinoidin und demselben Ammoniaksalze ungefähr drei Stunden reiben und kneten, ehe ich meinen Zweck erreichte, so dass ich anfangs die Richtigkeit meiner orsten Beobachtung bezweifelte. Obgleich es nun für die Kenntniss des Chinoidins eine wichtige Thatsache ist, dass es bei gewöhnlicher Temperatur aus den Auflösungen von Ammoniaksalzen Ammoniak entwickelt und aufgelöst wird, so ist diese Behandlung doch kein practisches Mittel, ein Chinoidin zu reinigen, weil dazu viel Zeit erfordert wird. Ich versuchte daher dieselbe Behandlung bei der Kochbitze, welche mich schnell zu der folgenden practischen Vorschrift leitete, ein Chinoidinum purum zu bereiten.

9 Theile Chinoidinum venale werden mit einer verdünnten Auflösung von 2 Theilen noutralen oxalsauren Ammoniaks in einem eiseren Topfe so lange gekocht, bis kein Ammoniak mehr ausgetrieben wird. $\mathrm{Da}$ sich der unauflösliche Theil während des Kochens theilweise an die Wände des Toptes ansetzt, muss man von Zeit zu Zeit destillirtes Wasser zusetzen, damit dieser Theil während des Kochens stets dureh Flüssigkeit bedeckt und also mit der Salzauflösung in Berührung bleibe. Sobald man keine Entwicklung von Ammoniak mehr wahrnimmt, lässt man die Flüssigkeit vollständig abkühlen und prüft, ob sie durch Zusatz von Wasser noch trübe wird. Ist dies der Fall, so verdünnt man so lange mit destillirtem Wasser, bis ein Theil der Flüssigkeit nach Filtration durch Zusatz von Wasser nicht mehr getrübt wird. Als dann wird die ganze Flüssigkeit filtrirt und in einer Abdampfschaale mit einem Ueberschuss von Aetznatron präcipitirt, das hierdurch gebildete klebrige Präcipitat kann durch gelinde Erwärmung aus der Fliissigkeit leicht auf dem Boden der Schale gesammelt werden, worauf man die hellere alkalische Flüssigkeit weggiesst und den Niederschlag in der Schaale wiederholt mit destillirtem Wasser abwäscht. Das so gereinigte Chinoidin, welches noch weich und klebrig ist, wird nun einige Zeit einer Temperatur von $100 \mathrm{bis} 110^{\circ} \mathrm{C}$. ausgesetzt, wodurch es langsam das innig gebundene Wasser verliert und endlich nach dem Abkühlen hart und zerreiblich wird. Die Vorschrift, oxalsaures Ammoniak zur Reinigung des Chinoidins zu gebrauchen, hat die Entfernung des Kalks 
zum Zwecke, womit das Chinoidin des Handels oft verunreinigt ist. (Tydschrift voor wetenschappelyke Pharmacie). Dr. Joh. Milller.

\title{
Chinovasaures Chinoidin.
}

\author{
Von J. E. de Vry.
}

Die Thatsache, dass viele hundert Pfunde Chinoidin und Chinovasäure in einigen Chininfabriken ungebraucht liegen, veranlasste mich zu untersuchen, ob es nicht möglich sei, beiden eine zweckmässige pharmaceutische Form zu geben. Die Klebrigkeit des, wenn auch gereinigten Chinoidins, macht daraus ein lästiges Präparat. Wenn man aber das rohe Chinoidin des Handels auflöst, indem man 9 Theile desselben mit einer verdünnten Auflösung von 2 Theilen Salmiak kocht und diese Auflösung, nachdem sie abgekühlt und filtrirt ist, mit einer kalten Auflösung von chinovasauren Kalk vermischt, so erbält man einen flockigen voluminösen Niederschlag von chinovasaurem Chinoidin, welches leicht auf Leinwand gesammelt und ausgepresst werden kann. Nachdem die ausgepresste Masse wiederholt mit Wasser ausgewaschen, wird sie auf Filtrirpapier ausgebreitet, bei ge linder Wärme getrocknet und dann zu Pulver gerieben. Man hat alsdann ein Mittel, welches leicht sowohl in Pulver als in Pillen verordnet werden kann, und worin tonische und fiebervertreibende Eigenschaften der China vereinigt sind. Die zu diesem Präparate nöthige Chinovasäure kann nicht allein aus Chininfabriken bezogen, sondern durch die Apotheker selbst leicht bereitet werden und zwar aus den Rückständen der zu den Decocten und Extracten gebrauchten Chinarinden, woraus durch Behandlung mit einer kalten dünnen Kalkmilch chinovasaurer Kalk bereitet werden kann, welcher durch Vermischung mit den durch Kochen von Chinoidin mit einer Auflösung von Salmiak erhaltenen kalten Auflösung von Chinoidin das chinovasaure Chinoidin liefert. Es ist selbstredend, dass man in diesem Falle kein oxalsaures Ammoniak zur Auflösung des Chinoidins gebrauchen kann.

Bei Gelegenheit der Bereitnng von chinovasaurem Chinoidin prüfte ich auch die Wirkung der Auflösung von neutralem chinovasauren Alkali auf die Auflösungen des Chinins und der Chinidinsalze, wobei mir schien, dass in beiden hierdurch ein Präcipitat von chinovasaurem Chinin und Chinidin gebildet wurde, aber keine Spur ron Krystallen wahrzunehmen 